\title{
Qualidade de vida, Bem-estar e Felicidade no Trabalho: sinônimos ou conceitos que se diferenciam?
}

\author{
Thais Cristine Farsen \\ Samantha de Toledo Martins Boehs \\ Andresa Darosci Silva Ribeiro \\ Vanderléia de Paula Biavati \\ Narbal Silva
}

\section{RESUMO}

O presente artigo objetivou realizar reflexões para compreender as similaridades e diferenciações entre os constructos qualidade de vida no trabalho, bem-estar e felicidade no trabalho. Foram analisados artigos e livros de origem nacional e internacional. A análise do material permitiu apontar que apesar da falta de consenso teórico e da utilização dos termos como sinônimos, especialmente entre "qualidade de vida e bem-estar" e "bem-estar e felicidade", verificou-se que são constructos diferentes, entretanto, complementares. Enquanto a qualidade de vida está mais voltada à saúde física e às questões objetivas que envolvem os seres humanos, a promoção de bem-estar e da felicidade suprem as lacunas relacionadas às emoções e sentimentos dos trabalhadores. 0 estudo possibilita esclarecimentos sobre os constructos apresentados, dando-lhes maior visibilidade e favorecendo seu uso adequado na literatura relacionada à saúde do trabalhador.

Palavras-chave: Qualidade de vida no trabalho; Bem-estar no trabalho; Felicidade no Trabalho.

\section{ABSTRACT}

\section{Quality of life, Well-being and Happiness at Work: Synonyms or different concepts?}

The present article aimed to carry out reflections with the purpose of understanding similarities and differences between the concepts of life quality at work, well-being and happiness at work. National and international articles and books have been analyzed. The analysis of the material has allowed to point out that, despite the lack of theoretical consensus and the use of those as synonyms, specially between "life quality and well-being" and "wellbeing and happiness", it has been pointed out that these are different concepts, although complementary. While life quality regards physical health and objective issues, the concepts of well-being and happiness promotion make up for the lack related to workers' emotions and feelings. The study allows clarification on the presented constructs, giving them greater visibility and favoring their adequate use in the literature related to the worker's health.

Keywords: life quality at work; well-being at work; happiness at work.

Os seres humanos em sua vida adulta passam boa parte do tempo trabalhando (Peiró \& Prieto, 2006). Por essas e outras razões, o trabalho se configura como categoria sociológica central na sociedade em que vivemos. Tal é o seu impacto, que ele se caracteriza como elemento vital para a construção da identidade, influenciando diretamente na forma como as pessoas se reconhecem e são reconhecidas (Antunes, 1995; Mow, 1987). Assim, se para a sobrevivência dos seres humanos o trabalho deve, em princípio, satisfazer as necessidades básicas, na perspectiva psicológica é uma categoria central no desenvolvimento do autoconceito e da autoestima (Zanelli, Silva \& Soares, 2010).

\section{Sobre os Autores}

T.C.F

orcid.org/0000-0001-9642-1587 Universidade Federal de Santa Catarina (UFSC) - Florianópolis SC

thais.farsen@gmail.com

\section{S.T.M.B.}

orcid.org/0000-0001-5741-056X

Universidade Federal de Santa

Catarina (UFSC) - Florianópolis, $\mathrm{SC}$

profsamantha.toledo@gmail.co $\mathrm{m}$

A.D.S.R

orcid.org/0000-0002-3263-5807

Universidade Federal de Santa

Catarina (UFSC) - Florianópolis, SC

andresa.darosci@gmail.com

V.P.B.

orcid.org/0000-0003-4945-767X Universidade Federal de Santa

Catarina (UFSC) - Florianópolis, SC

vbiavati@terra.com.br

N.S.

orcid.org/0000-0003-2841-3440

Universidade Federal de Santa Catarina (UFSC) - Florianópolis SC

narbal.silva@globo.com

\section{Direitos Autorais}

Este é um artigo de acesso aberto e pode ser reproduzido livremente, distribuído,

transmitido ou modificado, por qualquer pessoa desde que usado sem fins comerciais. 0 trabalho é disponibilizado sob a licença Creative Commons CCBY-NC. 
Apesar de nos dias atuais o trabalho estar sendo naturalmente considerado como central na vida das pessoas, tal centralidade é uma construção do discurso que surgiu à medida que o capitalismo foi criando novas necessidades de integração do trabalhador ao mundo do capital fazendo com que o trabalho fosse elevado então à condição de categoriachave na definição dos seres humanos (Bendassolli, 2009). A centralidade pode ser compreendida a partir do grau de importância que o trabalho tem na vida de uma pessoa em determinado momento e inclui dois componentes: um valorativo, a centralidade absoluta do trabalho, que mede o valor atribuído pelos sujeitos considerando a importância do trabalho na vida e outro sobre a centralidade relativa do trabalho, comparada a outras esferas importantes na vida (Mow, 1987; Tolfo \& Piccinni 2007).

As transformações na conjuntura social, política, econômica e cultural configurada pela progressiva e intensa transição da sociedade industrial para a sociedade do conhecimento, redefiniram os modos de produzir e servir fazendo com que as pessoas passassem a conceber de forma diferente seus projetos de vida, tornando-se cada vez mais individualizadas e sobrecarregadas (Castells, 1999). Como consequência dessa mudança de concepção, Snyder e Lopez (2009) argumentam que o estresse, a infelicidade e o sofrimento psicológico no trabalho têm se tornado cada vez mais presentes, o que tem endereçado ao aumento das taxas de absenteísmo, dos riscos de acidentes e afastamentos por doenças físicas e psíquicas relacionadas ao trabalho.

Ao considerar o trabalho como dimensão central na vida humana, cabe refletir sobre a seguinte pergunta: como o trabalho pode ser central na vida do homem e não lhe prover qualidade de vida, bem-estar e felicidade? Com intuito de construir respostas para essa questão, pesquisadores, acadêmicos e profissionais têm procurado compreender os conceitos qualidade de vida, bem-estar e felicidade e suas tênues interfaces, com o propósito de subsidiar políticas e práticas de gestão de pessoas, orientadas à saúde física e psíquica dos trabalhadores.

A ênfase na saúde física e psíquica do trabalhador tem sido pilar básico à construção de organizações saudáveis, o que, segundo Salanova (2008), se caracteriza como ambientes de trabalho onde são realizados esforços sistemáticos, planejados e proativos para melhorar a saúde dos seres humanos, por meio da organização saudável das tarefas, do ambiente físico e psicossocial, e das estratégias de equilíbrio trabalho/outros espaços de vida. Para Silva, Boehs e Cugnier (2017, p. 50), "as organizações saudáveis são concebidas como construções humanas, dotadas de propósitos significativos, que são percebidos, sentidos e compartilhados".
O princípio base de uma organização saudável é o equilíbrio e alinhamento entre qualidade de vida, bem-estar e felicidade, produtividade, qualidade e rentabilidade organizacional (Csikszentmihalyi, 2004). Assim, os ganhos possibilitados ao trabalhador que está inserido em uma organização saudável envolvem direta ou indiretamente os três fenômenos foco deste artigo. No entanto, embora para o processo de construção da organização saudável seja necessário considerar esses fenômenos, verifica-se uma dificuldade na sua delimitação. Isso porque na literatura os conceitos de qualidade de vida e bem-estar ora são tratados como sinônimos, ora como conceitos distintos (Silva \& Ferreira, 2013). 0 mesmo ocorre entre bem-estar e felicidade comumente utilizados na literatura como sinônimos (Contreras \& Esguerra, 2006; Rosa \& Hutz, 2008; Paschoal, Torres \& Porto, 2010; Traldi \& Demo, 2012; Santos \& Ceballos, 2013). Em alguns casos o constructo bem-estar é tratado como a avaliação subjetiva da qualidade de vida e da felicidade (Traldi \& Demo, 2012) e em outros ainda como o estudo científico da felicidade (Paschoal et al., 2010). Ainda tem abordagens que consideram que na academia o uso dos termos bem-estar subjetivo ou psicológico seja sinônimo de felicidade (Albuquerque \& Tróccoli, 2004; Diener, 2000).

A partir das informações apresentadas, pautando-se na existência de contextos laborais onde ocorre a centralidade do trabalho na vida humana e da necessidade de construção de organizações mais saudáveis, apresenta-se o objetivo do presente estudo, que é construir reflexões teóricas que possam clarificar as similaridades e distinções entre os constructos qualidade de vida, bem-estar e felicidade no trabalho. Nessa perspectiva, espera-se que o texto contribua para o avanço do conhecimento ao estabelecer interfaces entre os fenômenos, buscando a delimitação do que significa cada um deles separadamente.

\section{QUALIDADE DE VIDA NO TRABALHO}

A promoção da qualidade de vida no trabalho é um campo incipiente que privilegia o respeito e a valorização da vida individual e coletiva (Sauer \& Rodriguez, 2014). Apesar de ser um termo amplamente utilizado na literatura e na prática das organizações, percebe-se algumas divergências teóricas e metodológicas acerca do que caracteriza a qualidade de vida no trabalho. Sampaio (2012) afirma que não existe um conceito chave para o termo e segundo o autor o que há é uma "noção de qualidade de vida no trabalho, ou seja, um 'guarda-chuva teórico' com consequências práticas, associado a outros fenômenos organizacionais e relacionados à saúde mental” (p.122).

Nessa mesma direção, ao constructo qualidade de vida no trabalho foi herdada a amplitude da definição mais geral 
de qualidade de vida, utilizada pela Organização Mundial da Saúde (OMS), que se refere a um estado de pleno bem-estar físico, mental e social e que, por isto, engloba aspectos diversos como motivação, satisfação, condições de trabalho, estresse, estilos de liderança, entre outros (Tolfo, 2008). Além disso, há quatro ênfases nos estudos sobre qualidade de vida no trabalho: a preocupação com o bem-estar e satisfação do trabalhador aliado ao aumento da produtividade; o envolvimento dos trabalhadores nas decisões e problemas do trabalho; a humanização do trabalho; e a forma de pensar sobre pessoas, trabalho e organizações (Tolfo, 2008).

Algumas correntes teóricas dão ênfase aos fatores pessoais que interferem na qualidade de vida. Guimarães (2015), por exemplo, afirma que a percepção da qualidade de vida é individual e subjetiva tendo relação com as percepções culturais e sociais dos seres humanos. Walton (1973) estabelece, ainda, oito dimensões que interferem na qualidade de vida. A primeira é a compensação adequada e justa, que descreve aspectos relacionados à equidade salarial interna e externa e aos benefícios oferecidos pela empresa; a segunda abarca as condições de trabalho, que devem ser seguras e saudáveis; a terceira refere-se às oportunidades de desenvolvimento das capacidades, que trata da autonomia, da possibilidade de aplicar habilidades variadas e obter informações sobre o processo total do trabalho; a quarta dimensão considera as oportunidades de crescimento e segurança, de se desenvolver na carreira e ter segurança no emprego; a quinta abrange a integração social na organização de trabalho, marcada pela ausência de preconceitos, pelo apoio dos grupos primários, o senso de comunidade, a abertura interpessoal e o igualitarismo; a sexta demarca a importância das normas e regras, respeito à privacidade pessoal e à adesão a padrões de igualdade; a sétima relaciona-se ao trabalho e espaço total da vida, mostrando que para haver qualidade de vida deve-se ter uma relação equilibrada entre o papel do trabalho e os outros níveis de vida do empregado, com possibilidade de tempo livre para a família, para os seus hobbies e atividades cívicas; a oitava e última dimensão envolve a relevância social da vida no trabalho, ou seja, a forma como a organização se posiciona frente ao ambiente onde atua, se é socialmente responsável, etc., fator que pode afetar o valor que os trabalhadores dão para o seu trabalho.

Em termos históricos, o conceito de qualidade de vida no trabalho tem como base de origem dois movimentos: a saúde do trabalhador e a gestão da qualidade e da produtividade (Limongi-França, 2015a). O termo vem sendo utilizado desde 1970, em empresas estadunidenses, além de terem sido realizados estudos e pesquisas no Canadá e na França. Conforme sua concepção, a qualidade de vida no trabalho é "a percepção de bem-estar pessoal no trabalho, composta de dimensões relativas às necessidades humanas, biológicas, psicológicas, sociais e organizacionais" (Limongi-França, 2015a, p. 550). Essa percepção pode ser alterada por meio de condições intrínsecas e extrínsecas. A primeira está relacionada a fatores pessoais como personalidade, história de vida e autoestima, enquanto as condições extrínsecas referem-se à comparação com grupos e pares ocupacionais, fatores socioeconômicos e às políticas e práticas de gestão de pessoas utilizadas nas organizações (Limongi-França, 2015a).

Para Tolfo, Silva e Luna (2009), a qualidade de vida no trabalho é "composta de conteúdos subjetivos (satisfação de necessidades intrínsecas) e objetivos (forma de organização e condições de trabalho)" (p.10). Sobre isso, Limongi-França (2015b) apresenta, ainda, que os principais desafios para a consolidação das ações e programas de gestão de qualidade de vida no trabalho nas organizações são: consolidação de modelos, qualificação dos técnicos, gestores e especialistas, ajuste do foco da gestão como processo e o fortalecimento das competências de bem-estar organizacional integradas ao bem-estar pessoal.

\section{DIMENSÕES DO BEM-ESTAR}

Os estudos e a compreensão dos aspectos positivos da experiência humana estão entre as principais preocupações da Psicologia do século XXI (Seligman \& Csikszentmihalyi, 2000). Nesse contexto, nas últimas três décadas, os pesquisadores têm se esforçado para construir conhecimentos que tragam evidências científicas sobre o bem-estar, transformando-o em um tema central, cujo propósito é a compreensão de fatores psicológicos que constroem e compõem uma vida saudável (Siqueira \& Padovam, 2008).

O conceito de bem-estar esteve inicialmente associado aos estudos da economia e relacionado ao significado de bem-estar material (Welfare), mas nos anos de 1960 a concepção transcendeu a dimensão de bem-estar econômico e se constituiu a partir de uma dimensão global, passando a ser considerado, além das condições materiais de existência, o bem-estar por meio de avaliações da vida como um todo, também incluindo aspectos mais subjetivos, o que repercutiu diretamente no aumento dos estudos sobre o bem-estar subjetivo ocorrido entre os anos de 1960 e 1980 (Galinha, 2008).

Desde então, o conceito de bem-estar tem sido estudado na área de conhecimento da psicologia, em especial no que se refere à Psicologia Positiva, a partir de distintas perspectivas de análise, as quais podem ser classificadas segundo Boehs e Silva (2017) em quatro áreas: bem-estar subjetivo, bem-estar psicológico, bem-estar social e bem- 
estar no trabalho. Os autores anteriormente referidos relatam que a mais antiga das abordagens se baseia no conceito de bem-estar subjetivo (BES), criado na década de 50 , orientado pela política do bem-estar social e pela demanda da criação de indicadores de qualidade de vida que considerassem a percepção humana como componente subjetivo dos seres humanos ao avaliarem suas qualidades de vida. O bem-estar subjetivo pode ser definido como a combinação resultante de afetos positivos, negativos e a satisfação geral com a vida (Diener, 1984).

A segunda abordagem, denominada bem-estar psicológico (BEP), está centrada no desenvolvimento das potencialidades humanas, autorrealização e desenvolvimento pessoal. Ryff, no ano de 1989, desenvolveu um trabalho pioneiro ao construir um instrumento que divide em seis dimensões centrais a saúde psicológica positiva, incluindo a autoaceitação, as relações positivas com os outros, a autonomia, o domínio do ambiente, o propósito na vida e o crescimento pessoal (Dierendock, Díaz, Rodrígues-Cavajal, Blanco \& Moreno-Jimenez, 2008; Siqueira \& Padovam, 2008). A autoaceitação se refere à autocrítica realizada de forma positiva com reconhecimento de suas limitações; as relações positivas se referem à capacidade de estabelecer relações sociais duradouras, de confiança e com significado; já a autonomia trata de estabelecer a individualidade em diversos contextos por meio da independência das próprias convicções e autoridade pessoal; o domínio do ambiente se caracteriza pela capacidade de controlar de maneira efetiva sua própria vida de modo que se satisfaçam os desejos e necessidades pessoais; o propósito na vida refere-se a ter metas e objetivos que permitam dotar de significado a própria vida e, por último, o crescimento pessoal, que é a intenção de desenvolver seu próprio potencial (Moscoso \& Alonso, 2013).

O bem-estar social é constituído por cinco dimensões, sendo a primeira a integração social, que é a avaliação da qualidade do relacionamento de uma pessoa com a sociedade. A segunda dimensão trata da percepção da sua aceitação social e a terceira (contribuição social) tem relação com o grau de consciência que um ser humano tem acerca da sua importância para determinado grupo social. Já a quarta dimensão se refere ao quanto o indivíduo acredita na possibilidade da construção de um contexto social para todos. A última dimensão corresponde a percepção da qualidade, organização e compreensão da sociedade na qual as pessoas estão inseridas. (Ferreira Novo, 2005).

Por fim, na última abordagem, denominada de bem-estar no trabalho (BET), o foco reside nos sentimentos que o ser humano nutre ao estabelecer vínculos com o trabalho e com a organização (Siqueira \& Padovam, 2008). O conceito de bem-estar no trabalho tem sido compreendido internacionalmente por meio da influência do modelo elaborado por Warr (1987). Tal autor considera que o bemestar no trabalho está no equilíbrio que o ambiente sócio laboral pode proporcionar ao trabalhador nos aspectos que envolvem recursos financeiros, segurança física, posição social valorizada em função do trabalho que exerce oportunidade e controle das atividades, oportunidade para desenvolver competências, resultados alcançados para o progresso social, variedade das tarefas desempenhadas, clareza e compreensão do ambiente de trabalho e oportunidade para estabelecer relações sociais (Silva, Borges, \& Barbosa, 2015).

No Brasil compreende-se o bem-estar no trabalho como um constructo psicológico de caráter multidimensional, que está integrado ao mesmo tempo por vínculos afetivos positivos com o trabalho (satisfação e envolvimento) e com a organização (comprometimento organizacional afetivo) (Siqueira \& Padovam, 2008). Outra forma de compreender o bem-estar no trabalho está relacionada com a prevalência de emoções positivas no trabalho, aliada à percepção de que o ser humano expressa e desenvolve potenciais e competências, avançando, desse modo, no alcance de seus propósitos de vida (Paschoal \& Tamayo, 2008). Nesta definição, estão inclusos os aspectos afetivos (emoções e humores) e aspectos cognitivos (percepção de expressividade e realização). O bem-estar no trabalho também pode ser concebido como sinônimo do conjunto de três fatores interligados, afeto positivo, a avaliação subjetiva da qualidade de vida e felicidade (Traldi \& Demo, 2012).

\section{FELICIDADE NO TRABALHO}

Desde a época dos filósofos gregos, como Sócrates, Aristóteles e Epicuro, até a atualidade, tem se construído conceitos com o objetivo de compreender a felicidade e o sentido da vida. Essa é a maior de todas as motivações humanas e se constitui um direito inalienável de toda e qualquer pessoa (Diener, 1984; Aristóteles, 1991). Numa perspectiva epistemológica de base humanista, de acordo com Abraham Maslow (1968), felicidade significa autoatualização e autorrealização, ou seja, a possibilidade de o indivíduo tornar-se aquilo que em essência deseja ser e alcançar e que o fará sentir-se feliz. Nessa direção, tanto no trabalho como em outros espaços de vida, a felicidade vai ao encontro das experiências de flow, que pode ser compreendida pelo propósito significativo, que endereça a uma reorientação temporal e espacial quando se está realizando alguma atividade com sentido (Csikszentmihalyi, 1990).

O livro "Authentic Happiness" escrito por Seligman, no ano de 2002, é um marco que estabelece reflexões sobre a Psicologia Positiva e aponta o conceito de felicidade como 
um dos pilares fundamentais desse campo de estudo. A partir dessa obra, pesquisadores de diversos países têm realizado estudos com o objetivo de descobrir o que as pessoas consideram "ser feliz" e em que medida são capazes de realizar plenamente suas potencialidades.

Para Snyder e Lopez (2009) o termo felicidade é pouco usado em trabalhos científicos, e na academia os estudos e pesquisas que versam sobre o tema, como exemplo, Nunes, Hutz e Giacomoni (2009), Rosa e Hutz (2008), Rodrigues (2007), Santos e Ceballos (2013) e Siqueira e Padovam (2008) têm usado o conceito de bem-estar subjetivo (BES) como sinônimo de felicidade. A compreensão e o uso dos conceitos de felicidade e de bem-estar como sinônimos podem ser identificadas nas pesquisas de Contreras e Esguerra (2006), que definem ambos os conceitos como emoção positiva duradoura revestida de estabilidade. É também o que fazem Paschoal, Torres e Porto (2010) ao utilizarem o constructo do bem-estar para se referirem ao estudo científico da felicidade.

Com vistas ao esclarecimento e estabelecimento de fronteiras entre os constructos, salienta-se que os estudos sobre a felicidade têm sido em geral orientados por duas perspectivas tradicionais: a hedônica e a eudaimônica. A primeira carrega consigo os significados conferidos ao conceito de bem-estar subjetivo, e na segunda a orientação constitutiva se dá por meio do conceito de bem-estar psicológico. Nessa ótica, hedônica, o bem-estar subjetivo resulta do conjunto preponderante de sentimentos positivos e revestidos de gratificação imediata (Freire, Zenhas, Tavares \& Iglésias, 2013).

Em outra direção, porém complementar, ancorada no eudaimonismo, no conceito de bem-estar psicológico a ênfase reside nas experiências de realização pessoal e de expressão do potencial dos seres humanos, o que também pode ser denominado de funcionamento psicológico positivo ou ótimo (Machado, 2010). Tal concepção a respeito do significado de felicidade, tem origem em Aristóteles, em especial no livro denominado de "Ética a Nicômaco" (Aristóteles, 1991). Na vertente construída pelo filósofo grego, felicidade significa viver uma vida orientada por propósitos significativos. Apoiados nessa premissa, estudiosos e pesquisadores que se orientam pelos pressupostos epistemológicos da Psicologia Positiva, caracterizam a felicidade como um processo contínuo e perene, revestido de sentido, o que tem como suposto básico o desenvolvimento das virtudes humanas (Freire et al., 2013). Associado ao crescimento e ao desenvolvimento pessoal e profissional tem-se o conceito de felicidade agregado ao significado e sentido no trabalho e em outros espaços de vida. Ou seja, para se viver de modo autêntico, virtuoso e íntegro se supõe uma vida revestida de vivências significativas e com sentido (Schweitzer, Gonçalves, Tolfo \& Silva, 2016; Steger, Frazier, Oishi \& Kaler; 2006).

Concepções emergentes de felicidade têm se ancorado nas perspectivas hedônica e eudaimônica, sendo vistas como complementares (Dolan, 2015; Keyes, 2005; Seligman, Steen, Park \& Peterson, 2005). A interface estabelecida integra ambas perspectivas no sentido de quanto maior a regularidade de sentimentos que proporcionem prazer ao ser humano, maior a possibilidade dessa felicidade ser duradoura (Ribeiro et al., 2017). Nessa ótica, Delle Fave et al. (2011) protagonizaram uma pesquisa com adultos de vários países onde foram investigadas as definições conceituais e as experiências subjetivas de felicidade dos pesquisados, níveis de felicidade e de significado em diversos espaços de vida, os fatores revestidos de propósito nas suas vidas e os níveis de satisfação com a vida, o que proporcionou descobertas sobre elementos das perspectivas hedônica e eudaimônica.

Em síntese, o conceito de felicidade agrega múltiplos significados, o que caracteriza as pesquisas como não lineares ou não consensuais (Averill \& More, 1993). A felicidade é conceituada desde o modo como percebemos a vida em geral, os aspectos mais significativos, o alcance de propósitos relevantes, de necessidades e expectativas importantes, até a felicidade como consequência do equilíbrio entre sentimentos positivos e negativos (Averill \& More, 1993; Emmons, 2003; Keyes, Shmotkin, \& Ryff, 2002). À guisa de ilustração das múltiplas possibilidades conceituais, Schueller e Seligman (2010) estabeleceram três alternativas diferentes para explicar felicidade, sendo elas: as emoções positivas e o prazer; o envolvimento; e, por fim, o significado. $\mathrm{Na}$ compreensão dos autores, os seres humanos cujas vidas contemplam estas características de modos intensos e positivos, tenderiam a vivenciar sentimentos preponderantes de satisfação na vida, de modo recorrente e perene.

o constructo felicidade, sendo caracterizado como um estado psicológico positivo, tem sido utilizado com baixa frequência na pesquisa acadêmica sobre as experiências dos seres humanos nas organizações. Entretanto, nas últimas duas décadas os estudos realizados sobre felicidade no trabalho têm apresentado como resultado maior desempenho daqueles trabalhadores que possuem um alto estado psicológico positivo. Tal constatação pode ser exemplificada pelas pesquisas realizadas por Wright e Cropanzano (2000) e Zelenski, Murphy e Jenkins (2008) que identificaram respectivamente que os trabalhadores felizes são os mais produtivos, sendo também menos propensos a demonstrar comportamentos de absenteísmo e rotatividade, e costumando agir de maneira positiva, indo além do exigido no trabalho. Dessa forma compreende-se que ao se investir na valorização das pessoas e nos seus propósitos, a 
tendência é que as organizações se tornem mais rentáveis por meio de resultados positivos (Fernandes, 2015). Em síntese, pessoas que apresentam um estado psicológico positivo, tendem a perceber e interpretar o seu ambiente de forma diferente, sendo mais otimistas e preparadas para os desafios futuros.

Dessa forma, a partir das conceituações apresentadas, compartilhamos do entendimento de que a felicidade é constituída por experiências recorrentes e duradouras de prazer imediato (presente), aliadas à construção de propósito (sentido genuíno e gratificante), ao longo do tempo (Dolan, 2015; Ribeiro \& Silva, no prelo). Na seção seguinte são tecidas reflexões acerca das similaridades e diferenciações dos conceitos apresentados.

\section{REFLEXÕES TEÓRICAS: SIMILARIDADES E DIFERENCIAÇÕES ENTRE OS CONCEITOS}

A partir da leitura de artigos e livros nacionais e internacionais, considerados como referência em relação aos temas Qualidade de Vida no trabalho, Bem-estar e Felicidade no trabalho, foram desenvolvidas análises das similaridades e diferenciações entre os termos, o que resultou em descobertas significativas.

A primeira constatação relaciona-se à maturidade conceitual dos fenômenos. Ou seja, enquanto os conceitos de qualidade de vida e de bem-estar no trabalho têm sido estudados há muitos anos e, dessa forma, explorados em maior profundidade, o constructo felicidade no trabalho é um tema relativamente novo no meio científico, o que exige a realização de mais estudos e pesquisas que possam contribuir à melhor compreensão deste fenômeno.

A segunda constatação evidencia a ausência de consenso entre os pesquisadores na diferenciação dos conceitos. Qualidade de vida e bem-estar, por exemplo, ora são tratados como sinônimos, ora como conceitos distintos (Silva \& Ferreira, 2013). Tal fato é evidenciado na compreensão de qualidade de vida no trabalho como sendo "a percepção de bem-estar pessoal no trabalho (...)" (LimongiFrança, 2015a, p.550), onde se trata o constructo qualidade de vida no trabalho como sinônimo de bem-estar. Isso também ocorre na definição de bem-estar, não raro utilizada como sinônimo de felicidade (Contreras \& Esguerra, 2006; Paschoal et al., 2010; Rosa \& Hutz, 2008; Santos \& Ceballos, 2013; Traldi \& Demo, 2012). Como exemplo, podemos citar o caso das definições que utilizam os termos avaliação subjetiva da qualidade de vida e da felicidade com o intuito de se reportar ao bem-estar (Traldi \& Demo, 2012), ou seja, tratam bem-estar como o resultado de práticas que envolvam qualidade de vida e felicidade. Outras concepções tratam o constructo bem-estar como o estudo científico da felicidade
(Paschoal et al., 2010), ou salientam ainda que, na academia, há o uso frequente dos termos bem-estar subjetivo ou psicológico como sinônimos de felicidade (Albuquerque \& Tróccoli, 2004; Diener, 2000). Já no senso comum, ou na prática em organizações, o termo felicidade tem sido mais utilizado. Tais visões denotam que, a depender do contexto, é utilizado um termo, e não outro, para se referir ao mesmo conceito.

A reflexão possível a partir de tais constatações é de que, embora distintos, os conceitos se caracterizam como constructos complementares, cujo propósito é o de construir "fazeres laborais" mais positivos, de modo a promover a saúde do trabalhador. Entretanto, é um equívoco utilizar os termos como similares, visto que percepções e sentimentos que denotam felicidade se tornam mais amplos e de ordem superior quando comparados a constructos como bem-estar subjetivo, bem-estar objetivo e bem-estar psicológico (Boehs \& Silva, 2017). Além disso, enquanto os diferentes tipos de bem-estar se caracterizam como antecedentes e originários em dimensões de qualidade de vida no trabalho, como também em outros espaços de vida, a felicidade constitui fenômeno de natureza psicossocial consequente, é aprendido e socialmente construído a partir de percepções, interpretações e sentimentos recorrentes, duradouros e perenes de bem-estar no trabalho, como também em outras instâncias de vida (Silva et al., 2015).

Um outro fator complicador nas definições de felicidade e de bem-estar, se refere aos conceitos de sentimentos e de emoções. Isto porque enquanto alguns pesquisadores usam o conceito de emoção para tratar os fenômenos (Contreras \& Esguerra, 2006; Jonker \& Merwe, 2013), outros se reportam a sentimentos (Aristóteles, 1991; Malvezzi, 2015; Silva \& Tolfo, 2012). Também podem ser encontrados na literatura autores que tratam emoção e sentimento como fenômenos de mesma ordem (Contreras \& Esguerra, 2006). Contudo, do ponto de vista constitutivo e operacional, os constructos emoção e sentimento, embora relacionados, são diferentes. As emoções e os sentimentos se inter-relacionam em algumas situações, em que pese não constituir regra geral. Enquanto as emoções estão intimamente relacionadas às percepções de prontidão para a ação do organismo e são ativadas por meio de sensações fisiológicas, os sentimentos são elaborados a partir de conhecimentos e de experiências já disponibilizadas na memória (Schachter, 1964). Outro ponto que os separa é que os sentimentos são socialmente construídos e as emoções instintivas. Gondim e Siqueira (2014) consideram que "os sentimentos não estariam tão relacionados à prontidão da ação quanto as emoções, mas à interpretação subjetiva da situação que, pela persistência do objeto na memória, faz perdurar o afeto em relação a ele" (p. 289). 
Ao salientar as diferenças entre sentimentos e emoções, a construção teórica possível é de que a felicidade é um sentimento, e não uma emoção. Ela é de ordem mais elevada ou superior ao bem-estar e à qualidade de vida. Felicidade é um estado superior, distinto de outros estados positivos, como alegria, qualidade de vida ou bem-estar (Malvezzi, 2015). Em consonância com isto, Silva et al. (2015) afirmam que o constructo felicidade se caracteriza como um estado psicológico, distinto, porém relacionado à qualidade de vida e bem-estar, que se encontra ancorado em sentimentos positivos estáveis, que são construídos histórica e socialmente, no tempo e no espaço.

É importante ressaltar que, diferente do que foi evidenciado na relação entre "felicidade e bem-estar" e "qualidade de vida e bem-estar", que são utilizados para definir um ao outro, o conceito de qualidade de vida no trabalho não está inserido no conceito de felicidade, e viceversa. Isso quer dizer que embora ambientes de trabalho que possibilitem qualidade de vida ao trabalhador possam impactar positivamente na sua percepção de felicidade, não há na literatura estudos empíricos que comprovem essa relação. Em termos teóricos essa relação pode ser embasada por meio do que Silva, Boehs e Cugnier (2017), propõe acerca da compreensão do conceito de felicidade nas organizações e no trabalho. Para os autores, a felicidade no trabalho se constitui a partir de três dimensões: a material de existência, a relacional e a espiritual. A dimensão que se relaciona à qualidade de vida no trabalho é a dimensão material de existência, onde o foco está no ambiente físico de trabalho, considerando como elementos fundamentais componentes que possam tipificar positivamente as condições objetivas dessa dimensão, tais como como equipamentos adequados, aspectos ergonômicos compatíveis, estruturas e processos conectados com necessidades e expectativas humanas, entre outros (Silva et al., 2017).

Ao analisar a origem e a natureza epistemológica dos constructos, verificou-se que os três fenômenos fazem parte da dimensão subjetiva da realidade social, localizando-se entre os paradigmas interpretativista e humanista radical discutidos por Burrel e Morgan (1979). Originalmente, o conceito de qualidade de vida no trabalho esteve articulado com os pressupostos dos programas de Qualidade Total e certificações ISO, sendo implantados com foco na produtividade das organizações, o que poderia caracterizá-lo como funcionalista. Entretanto, os programas de qualidade de vida no trabalho estão atrelados a uma concepção de organização do trabalho, na qual é considerado o atendimento das necessidades e das expectativas humanas, o que implica não focar exclusivamente a produtividade e a rentabilidade nas organizações (Sampaio, 2012). Dessa forma, considera-se o fenômeno localizado nas mesmas instâncias paradigmáticas onde se encontram alojados os conceitos de bem-estar e de felicidade no trabalho.

Outra reflexão teórica possível a partir do entendimento e das relações entre os três constructos chaves do presente artigo, é de que a qualidade de vida é construída por meio de relações dinâmicas e evolucionárias, construídas a partir de políticas e práticas organizacionais que fornecem condições favoráveis para a saúde do trabalhador, o que, por sua vez, pode estimular a construção de sentimentos positivos em relação ao trabalho, como a felicidade, e a sensação de bemestar. A Figura 1 sintetiza as reflexões realizadas no presente texto.

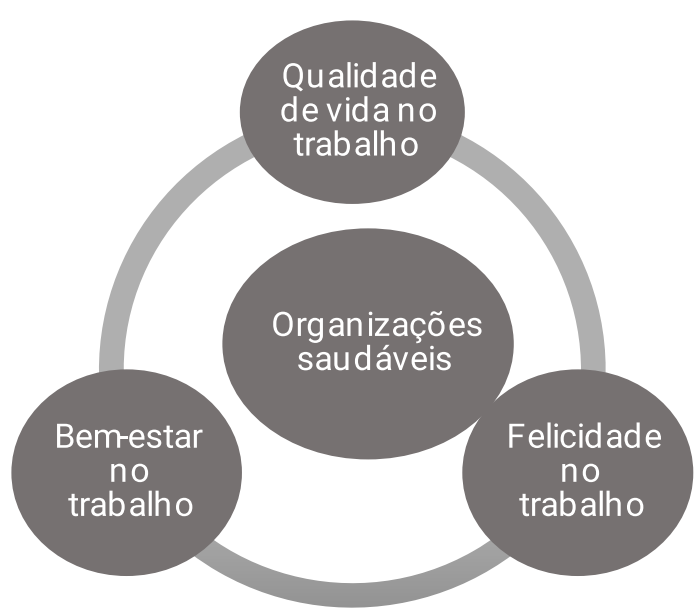

Figura 1.Qualidade de vida, bem estar e felicidade, elementos fundamentais para a construção de organizações saudáveis.

A Figura 1 apresentada anteriormente explicita a relação entre qualidade de vida, bem-estar e felicidade no trabalho como promotora de saúde ao trabalhador e componente chave para a construção de organizações saudáveis. Ou seja, a junção de desses fenômenos possibilita a construção de ambientes laborais saudáveis. Essa proposição vai ao encontro do que é trazido por Zanelli, Silva \& Tolfo (2011, p. 25) de que "a materialização de organizações saudáveis, por meio da construção de ambientes físicos e psicossociais promotores da felicidade humana possui, como pressupostos culturais, entre outros, aqueles que endereçam à qualidade de vida no trabalho e nos demais espaços da vida pessoal".

Apesar da falta de consenso teórico e da utilização dos termos como sinônimos, especialmente das relações entre "qualidade de vida e bem-estar" e "bem-estar e felicidade", salienta-se que estes são sim constructos diferentes, entretanto, complementares. Percebe-se que a qualidade de vida está mais voltada à saúde física e às questões 


\section{\# ET PSICOLOGIA}

Andresa Darosci Silva Ribeiro, Narbal Silva, Samantha de Toledo Martins Boehs, Thaís Cristine Farsen e Vanderléia de Paula Biavati objetivas, tais como aspectos ergonômicos e nutricionais, e menos relacionada com emoções e sentimentos. Nesse sentido, a promoção de bem-estar e da felicidade, conceitos considerados mais subjetivos, supre as lacunas relacionadas às emoções e sentimentos dos trabalhadores, pois inclui as questões subjetivas menos atendidas pela promoção de qualidade de vida no trabalho. Ao final compreende-se que a composição promovida pelos três fenômenos é que promoverá a possibilidade de construção de uma organização saudável, onde o princípio base é o equilíbrio e alinhamento entre qualidade de vida, bem-estar e felicidade, produtividade, qualidade e rentabilidade organizacional (Csikszentmihalyi, 2004).

\section{CONSIDERAÇÕES FINAIS}

A partir das discussões realizadas sobre os constructos qualidade de vida, bem-estar e felicidade no trabalho, evidencia-se que, embora alguns autores se esforcem para construir delimitações, ainda existem inconsistências teóricas que unem os três fenômenos e os apresentam de modo equivocado como sinônimos. Uma possibilidade para evitar esses problemas nos estudos que versam sobre o assunto seria a apresentação das abordagens epistemológicas, ontológicas, metodológicas e de natureza humana que os guiam. Tal ação pode proporcionar coerência científica, auxiliando para o desenvolvimento de pesquisas consistentes, que esclareçam as distinções e diferenciações entre os conceitos, e auxiliem na construção de estudos coerentes, que permitam visibilidade aos fenômenos.

Ao elaborar o presente estudo foram percebidas algumas lacunas referentes aos fenômenos estudados, em especial ao bem-estar e à felicidade no trabalho, ainda recentes na literatura. Nesse sentido, como sugestões para novos estudos destaca-se a realização de pesquisas empíricas que tenham como propósito mensurar o bem-estar e a felicidade no trabalho após a realização de intervenções que visem promover esses aspectos. Além disso, a realização de pesquisas qualitativas que enderecem à compreensão sobre o que é felicidade no trabalho e como ela é demonstrada pelas pessoas, se faz necessária.

$\mathrm{Na}$ tentativa de respostas para a pergunta feita inicialmente: Como o trabalho pode ser central na vida do homem e não the prover qualidade de vida, bem-estar e felicidade? Faz-se a seguinte reflexão: 0 trabalho torna-se verdadeiramente central na medida em que proporciona ao trabalhador condições que viabilizam o desenvolvimento da autoestima, do autoconceito, de realização, de crescimento, sendo fonte de satisfação, qualidade de vida, bem-estar e felicidade. Do contrário, será central somente no sentido do tempo despendido no trabalho, deixando de cumprir funções psicológicas relevantes e de construção de sentimentos preponderantemente positivos, que favoreçam o equilíbrio saudável entre trabalho e demais espaços de vida.

Na prática, os fenômenos analisados podem auxiliar na construção de organizações com características e práticas saudáveis, uma vez que tem como foco a saúde biopsicossocial dos trabalhadores. Além disso, buscar planejar atividades que vão ao encontro tanto das competências individuais quanto dos objetivos organizacionais proporciona significado positivo aos trabalhadores o que facilita a sua realização profissional.

\section{CONTRIBUIÇÃO DE CADA AUTOR}

T.C.F contribuiu na introdução do artigo, nos conceitos de qualidade de vida no trabalho, nas reflexões teóricas bem como na revisão e edição do texto. S.T.M.B. contribuiu na introdução do artigo, nas dimensões do Bem-estar, nas reflexões teóricas bem como na revisão e edição do texto . A. D. S. R.. contribuiu na introdução do artigo, nos conceitos de Felicidade no trabalho e nas reflexões teóricas. V.P.V. contribuiu nas dimensões do Bem-estar e nas reflexões teóricas. N.S. foi responsável pela supervisão referentes aos aspectos teóricos inseridos no texto.

\section{DECLARAÇÃO DE CONFLITOS DE INTERESSES}

Os autores declaram que não há conflitos de interesses no presente artigo.

\section{REFERÊNCIAS}

Albuquerque, A. S., \& Tróccoli, B. T. (2004). Desenvolvimento de uma escala de bem-estar subjetivo. Psicologia: Teoria e Pesquisa, 20(2), 153-164. http://dx.doi.org/10.1590/ S0102-37722004000200008

Antunes, R. (1995). Adeus ao trabalho? Ensaios sobre as metamorfoses e a centralidade do mundo do trabalho. Campinas, SP: Cortez.

Aristóteles. (1991). Ética a Nicômaco. Os pensadores, v.2. (4a.ed.). São Paulo: Nova Cultural.

Averill, J., \& More, T. (1993). Happiness. In Lewis, M.\& Haviland, J. (Eds.), Handbook of emotions. New York: The Guilford Press.

Bendassolli, P. F. (2009). Psicologia e trabalho: Apropriações e significados. São Paulo: Cengage Learning.

Boehs, S. T. M., \& Silva, N. (2017). Bem-estar, felicidade e satisfação de vida na aposentadoria: Construindo reflexões. Em S. T. M. Boehs \& N. Silva (Orgs), Psicologia Positiva nas Organizações e no Trabalho - conceitos fundamentais e sentidos aplicados (pp. 208-224). ( $1^{\text {a }}$ ed.) São Paulo: Vetor. 
Burrel, G., \& Morgan, G. (1979). Sociological Paradigms and Organisational Analysis. Heineman, London.

Castells, M. (1999). A sociedade em rede. São Paulo: Paz e Terra.

Contreras, F., \& Esguerra, G. (2006). Psicología positiva: Una nueva perspectiva en psicología. Diversitas, 2(2), 311-319.

Csikszentmihalyi, M. (1990). Flow: The psychology of optimal experience (1 st ed.). ISBN 978-0-06-016253-5. New York: Harper Perennial.

Csikszentmihalyi, M. (2004). Gestão qualificada: A conexão entre felicidade e negócios. Porto Alegre: Bookmam.

Diener, E. (1984). Subjective Well-Being. Psychological Bulletin, 95, 542-575.

Diener, E. (2000). Subjective well-being: The science of happiness, and a proposal for national index. American Psychologist, 55(1), 34-43.

Dolan, P. (2015). Felicidade Construída: como encontrar prazer e propósito no dia a dia. Rio de Janeiro: Objetiva.

Emmons, R. (2003). Personal goals, life meaning, and virtue: Wellsprings of positive life. In C. Keyes \& J. Haidt (Eds.), Flourishing: Positive psychology and the life well-lived. Washington, DC: American Psychological Association.

Fernandes, M. (2015). Felicidade dá lucro: Lições de um dos líderes empresariais mais admirados do Brasil. São Paulo: Portfolio-Penguin.

Ferreira Novo, R. (2005). Bem-estar e psicologia: Conceitos e propostas de avaliação. Revista Iberoamericana de Diagnóstico y Evaluación - e Avaliação Psicológica, 2(20), 183-203.

Freire, T., Zenhas, F., Tavares, D., \& Iglésias, C. (2013). Felicidade hedónica e eudaimónica: Um estudo com adolescentes portugueses. Análise Psicológica, 31(4). https://doi.org/10.14417/ap.595

Galinha, I. (2008). Bem-estar subjectivo: Factores cognitivos, afectivos e contextuais. Coimbra: Quarteto Editora.

Gondim, M. G., \& Siqueira, M. M. M. (2014). Emoções e afetos no Trabalho. Em J. C. Zanelli, J. E. Borges-Andrade \& A. V. B Bastos (Orgs.) Psicologia, Organizações e Trabalho no Brasil. (pp. 285-315, $2^{\text {a }}$ Ed.). Porto Alegre: Artmed.

Guimarães, L. A. M. (2015). Qualidade de vida e psicologia da saúde ocupacional. Em A. J. N. Ogata (Org.). Temas avançados em qualidade de vida. (pp. 87-108) Londrina: Midiograf.

Jonker, C., \& Merwe, A. Van der. (2013). Emotion episodes of Afrikaans-speaking employees in the workplace. SA Journal of Industrial Psychology, 39(1), 12 páginas. https:// doi.org/10.4102/sajip.v39i1.1006
Keyes, C. L. M. (1998). Social well-being. Social Psychology Quarterly, 61(2), 121-140. http://dx.doi.org/ $10.2307 / 2787065$

Keyes, C. L. M. (2005). Mental illness and/or mental health? Investigating axioms of the complete state model of health. Journal of Counseling and Clinical Psychology, 73(3), 539-548. http://dx.doi.org/10.1037/0022-006X. 73.3.539

Keyes, C., Shmotkin, D., \& Ryff, C. (2002). Optimizing wellbeing: The empirical encounter of two traditions. Journal of Personality and Social Psychology, 82(6), 1007-1022. http://dx.doi.org/10.1037//0022-3514.82.6.1007

Limongi-França, A. C. (2015a). Qualidade de vida no trabalho. Em P. F. Bendassoli, P. F., \& J. E. Borges-Andrade, J. E. (Orgs.). Dicionário de Psicologia do Trabalho e das Organizações. São Paulo: Casa do Psicólogo.

Limongi-França, A. C. (2015b). Gestão da qualidade de vida no trabalho: Evolução, aplicação e soluções da metodologia biopsicossocial e organizacional - BPSO96. Em A. J. N. Ogata (Org.). Temas avançados em qualidade de vida. (pp. 65-86). Londrina: Midiograf.

Machado, W. de L. (2010). Escala de bem-estar psicológico: Adaptação para o português brasileiro e evidências de validade. Dissertação de Mestrado. Universidade Federal do Rio Grande do Sul, Porto Alegre.

Malvezzi, S. (2015). Felicidade no Trabalho. Em P. F. Bendassolli, P. F. \& J. E. Borges-Andrade, J. E. (Orgs). Dicionário de psicologia do trabalho e das organizações. São Paulo: Casa do Psicólogo. 349-355.

Maslow, A. (1968). Introdução à psicologia do ser. (2a ed.) Rio de Janeiro: Eldorado.

Meaning of Work International Research Team - MOW (1987). The meaning of work. London: Academic Press.

Moscoso, S., \& Alonso, P. (2013). El Bienestar laboral. In L. M. Cantera, S. Pallarés, \& C. Selva (compiladoras). Del malestar al bienestar laboral. Amentia Editorial, Barcelona.

Nunes, C. H. S., Hutz, C. S., \& Giacomoni, C. H. (2009). Associação entre bem-estar subjetivo e personalidade no modelo dos cinco grandes fatores. Avaliação Psicológica, 8(1), 99-108.

Paschoal, T., \& Tamayo, A. (2008). Construção e validação da escala de bem-estar no trabalho. Avaliação Psicológica, 7(1), 11-22.

Paschoal, T., Torres, C. V., \& Porto, J. B. (2010). Felicidade no trabalho: Relações com suporte organizacional e suporte social. Revista de Administração Contemporânea - RAC, 14(6), 1054-1072. http://dx.doi.org/10.1590/S141565552010000700005 
Peiró, J. M., \& Prieto, F. A. (2006). Tratado de psicologia del trabajo: Aspectos psicosociales del trabajo. Madrid: Editorial Sintesis.

Ribeiro, A. D. S., Boehs, S. de T. M., Farsen, T. C., \& Biavati, V. de P. (2017) Felicidade, Bem-estar e Qualidade de Vida no Trabalho. Em S. T. M. Boehs, \& N. Silva (Org-s.). Psicologia Positiva nas Organizações e no Trabalho - conceitos fundamentais e sentidos aplicados. (pp. 156-171) (1 ed.). São Paulo: Vetor.

Ribeiro, A. D. S., \& Silva, N. (no prelo). Significados de felicidade em pesquisas orientadas pelos pressupostos epistemológicos da psicologia positiva em organizações e no trabalho. Revista Psicologia desde el Caribe.

Rodrigues, A. (2007). O bem-estar subjetivo de comerciantes e comerciários de Ribeirão Preto e Região. Dissertação. Universidade de São Paulo. http://dx.doi.org/10.11606/D. 59.2007.tde-15102007-113421

Rosa, F. H., \& Hutz, C. S. (2008). Psicologia positiva em ambientes militares: Bem-estar subjetivo entre cadetes do Exército Brasileiro. Arquivos Brasileiros de Psicologia, 60(2), 157-171.

Ryff, C. D. (1989). Happiness is everything, or is it? Explorations on the meaning of psychological well-being. Journal of Personality and Social Psychology, 57, 10691081. http://dx.doi.org/10.1037/0022-3514.57.6.1069

Salanova, M. (2008). Organizaciones saludables y desarrollo de recursos humanos. Estudios Financieros, 303, 179214.

Sampaio, J. R. (2012). Qualidade de vida no trabalho: Perspectivas e desafios atuais. Revista Psicologia Organizações e Trabalho, 12(1), 121-136.

Santos, G. B., \& Ceballos, A. G. C. de. (2013). Bem-estar no trabalho: Estudo de revisão. Psicologia em Estudo, 18(2), 247-255. 73722013000200006

Sauer, G. C., \& Rodriguez, S. Y. S. (2014). Da qualidade de vida à qualidade de vida no trabalho: Um resgate histórico e prático. Revista de Psicologia da IMED, 6(2), 98-106. http:// dx.doi.org/10.18256/2175-5027/psico-imed.v6n2p98-106

Schachter, S. (1964). The interaction of cognitiveand physiological determinants of emotional state. In $\mathrm{L}$. Berkowitz (Ed.) Advancesin experimental social psychology. (pp. 49-80). New York: Academic Press.

Schueller, S. M., \& Seligman, M. E. P. (2010). Pursuit of pleasure, engagement, and meaning: Relationships to subjective and objective measures of well-being. Journal of Positive Psychology, 5(4), 253-263. http://dx.doi.org/ 10.1080/17439761003794130

Schweitzer, L., Gonçalves, J., Tolfo, S. R., \& Silva, N. (2016). Bases epistemológicas sobre sentido(s) e significado(s) do trabalho em estudos nacionais. Revista Psicologia Organizações e Trabalho, 16(1), 103-116.
Seligman, M. E. P. (2002). Authentic happiness: Using the new positive psychology to realize your potential for lasting fulfillment. London: Nicholas Brealey.

Seligman, M. E. P., \& Csikszentmihalyi, M. (2000). Positive psychology: An introduction. American Psychologist, 55, 514. http://dx.doi.org/10.1037/0003-066X.55.1.5

Seligman, M. E. P., Steen, T. A., Park, N., \& Peterson, C. (2005). Positive psychology progress empirical validation of interventions. The American Psychologist, 60(5), 410-421. http://dx.doi.org/10.1037/0003-066X.60.5.410

Silva, C. A. da, \& Ferreira, M. C. (2013). Dimensões e indicadores da qualidade de vida e do bem-estar no trabalho. Psicologia: Teoria e Pesquisa, 29(3), 331-339. https://dx.doi.org/10.1590/S0102-37722013000300011

Silva, N., Boehs, S. T. M., \& Cugnier, J. S. (2017). Psicologia positiva aplicada às organizações e ao trabalho Conceitos fundamentais e sentidos aplicados. Em S. de T. M. Boehs, \& N. Silva (Orgs.). Psicologia positiva nas organizações e no trabalho. (pp. 42-61) (1 ed.). São Paulo: Vetor.

Silva, N., \& Tolfo, S. R. (2012). Trabalho significativo e felicidade humana: Explorando aproximações. Revista Psicologia: Organizações e Trabalho, 12(3), 341-354.

Silva, N., Tolfo, S. R., López, A. S., \& Cedenõ, A. G. (2015). Psicologia positiva nas organizações, no trabalho e em outros espaços de vida. In L. Godoy. \& E. Ansoleaga. (Compiladoras). Um campo em tensíon o tensíon entre campos: Psicologia de lãs organizaciones y del trabajo em Iberoamérica. (pp. 389-401). Chile: RiL Editores.

Silva, S. S. da, Borges, L. de O., \& Barbosa, S. da C. (2015). Bem-estar no trabalho. Em P. F. Bendassolli, \& J. E. BorgesAndrade (Orgs.). Dicionário de psicologia do trabalho e das organizações. São Paulo: Casa do Psicólogo.

Siqueira, M. M. M., \& Padovam, V. A. R. (2008). Bases teóricas de bem-estar subjetivo, bem-estar psicológico e bemestar no trabalho. Psicologia: Teoria e Pesquisa, 24(2), 201-209. http://dx.doi.org/10.1590/S010237722008000200010.

Snyder, C. R., \& Lopez, S. J. (2009). Psicologia positiva: Uma abordagem científica e prática das qualidades humanas. Em R. C. Costa (Trad.). Porto Alegre: Artmed.

Steger, M., Frazier, P., Oishi, S., \& Kaler, M. (2006). The meaning in life questionnaire: Assessing the presence of and search for meaning in life the meaning in life. Journal of counseling psychology, 53(1), 80-93. http://dx.doi.org/ 10.1037/0022-0167.53.1.80

Tolfo, S. R. (2008). Qualidade de Vida no Trabalho. Em A. Laner, J. B. Cruz Jr. Indivíduo, organizações e trabalho. Ijuí: Editora Universidade de ljuí.

Tolfo, S. R., \& Piccinini, V. (2007). Sentidos e significados do trabalho: Explorando conceitos, variáveis e estudos empíricos brasileiros. Psicologia e Sociedade, 19(spe), 3846. https://doi.org/10.1590/s0102-71822007000400007 
Tolfo, S. R., Silva, N., \& Luna, I. N. (2009). Cultura organizacional, identidade e qualidade de vida no trabalho: Articulações e sugestões de pesquisas em organizações. Pesquisas e Práticas Psicossociais, 4(1).

Traldi, M. T. F., \& Demo, G. (2012). Comprometimento, bemestar e satisfação dos professores de administração de uma universidade federal. REAd. Revista Eletrônica de Administração, 18(2), 290-316. http://dx.doi.org/10.1590/ S1413-23112012000200001

van Dierendonck, D., Díaz, D., Rodríguez-Carvajal, R., Blanco, A., \& Moreno-Jiménez, B. (2008). Ryff's six-factor model of psychological well-being, a Spanish exploration. Social Indicators Research, 87(3), 473-479. http://dx.doi.org/ $10.1007 / \mathrm{s} 11205-007-9174-7$

Walton, R. E. (1973). Quality of working life: What is it?. Sloan Management, 15(1), 11-21.

Warr, P. (1987). Work, unemployment and mental health. New York: Claredon Press.

Wright, T. A., \& Cropanzano, R. (2000). Psychological wellbeing and job satisfaction as predictors of job performance. Journal of Occupational Health Psychology, 5, 84-94. http://dx.doi.org/10.1037//1076-8998.5.1.84
Zanelli, J. C., Silva N., \& Soares, D. H. P. (2010). Orientação para aposentadoria nas organizações de trabalho: Construção de projetos para o pós-carreira. Porto Alegre: Artmed.

Zanelli, J., Silva, N., \& Tolfo, S. R. (orgs.). (2011) Processos psicossociais nas organizações e no trabalho. Itatiba: Casa do Psicólogo.

Zelenski, J. M., Murphy, S. A., \& Jenkins, D. A. (2008). The happy-productive worker thesis revisited. Journal of Happiness Studies, 9, 521-537. http://dx.doi.org/10.1007/ s10902-008-9087-4 